\title{
An improved inventory of polychlorinated biphenyls in China: A case study on PCB-153
}

\author{
Yue $\mathrm{Xu}^{\mathrm{a}}$, Chongguo Tian ${ }^{\mathrm{b}, *}$, Xiaoping Wang ${ }^{\mathrm{c}}$, Jianmin $\mathrm{Ma}^{\mathrm{d}}$, Jianhui Tang ${ }^{\mathrm{b}}$, Yingjun Chen ${ }^{\mathrm{e}}$, \\ Jun $\mathrm{Li}^{\mathrm{c}}$, Gan Zhang ${ }^{\mathrm{c}}$ \\ ${ }^{a}$ State Key Laboratory of Environmental Geochemistry, Institute of Geochemistry, Chinese Academy of Sciences, Guiyang 550002, China \\ ${ }^{\mathrm{b}}$ Key Laboratory of Coastal Zone Environmental Processes and Ecological Remediation, Yantai Institute of Coastal Zone Research, Chinese Academy of Sciences, Yantai, \\ 264003, China \\ ${ }^{\mathrm{c}}$ State Key Laboratory of Organic Geochemistry, Guangzhou Institute of Geochemistry, Chinese Academy of Sciences, Guangzhou, 510640, China \\ ${ }^{\mathrm{d}}$ Laboratory for Earth Surface Processes, College of Urban and Environment Sciences, Peking University, Beijing, 100871, China \\ e Key Laboratory of Cities' Mitigation and Adaptation to Climate Change (China Meteorological Administration), State Key Laboratory of Pollution Control and Resources \\ Reuse, College of Environmental Science and Engineering, Tongii University, Shanghai, 200092, China
}

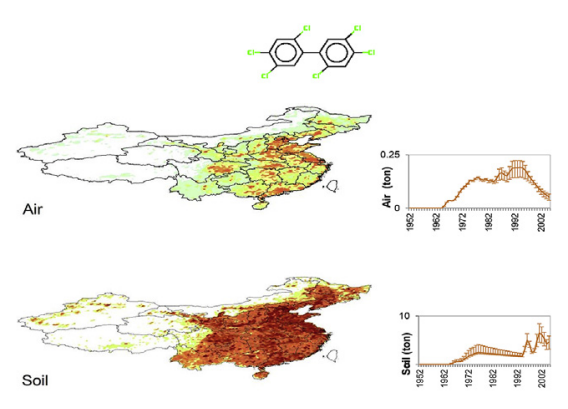

A R T I C L E I N F O

\section{Keywords:}

PCB-153

Emission inventory

China

\begin{abstract}
A B S T R A C T
Emission inventory of pollutants is essential for the environmental fate study and management of the pollutant. To construct a reasonable PCB (polychlorinated biphenyls) inventory in China, this study estimates PCB usage and emission using power generating capacity, installed capacity of power plants and transformer substations, population density and GDP as surrogates. Inventory of representative PCB (PCB-153) with a resolution of $1 / 4^{\circ}$ latitude $\times 1 / 4^{\circ}$ longitude in China from 1952 to 2005 was generated and assessed as an example. Totally, about $20.3 \mathrm{kt}$ PCBs were applied in China, of which $179 \mathrm{t}$ were PCB-153. By the end of 2005, most of them (56.4\%) were emitted into the soil, $2.7 \%$ entered the air, and about $20.8 \%$ was sealed in storage site or still in service. Historical emissions exhibited increasing trends after 1968, 1984 and 1994, which were mainly associated with usage or disposal processes. Although primary emission has been declined since 2005, the influence of secondary emission from soils, unintentionally produced PCBs (UP-PCB), and reemission from storage sites could be a longlasting issue in the future. This new emission inventory improves previous PCB emission inventory significantly, which underestimated PCB emission in China considerably.
\end{abstract}

\footnotetext{
* Corresponding author. Yantai Institute of Coastal Zone Research, CAS, China.

E-mail address: cgtian@yic.ac.cn (C. Tian).
} 


\section{Introduction}

Polychlorinated biphenyls (PCBs) are a group of synthetic organic compounds widely used as dielectric fluids, waxes, additives or other products before the 1970s. Due to persistency, toxicity, bioaccumulation, and long-range atmospheric transport (LRAT) potential, they are listed as the first batch of persistent organic pollutants (POPs) in the Stockholm Convention. Signatory countries are required to reduce and gradually eliminate the release of POPs into the environment. Signed and ratified the Convention in 2004, the scientific community in China has made great progress in the study of POPs for the past 14 years (Liu et al., 2016), although the information at the national level regarding PCB usage, emission, and residue is still limited (Xing et al., 2005; Ren et al., 2007; Cui et al., 2015).

Assessment of PCB budget, including use, stock, emission, is an important task for the implementation of the Stockholm Convention (Breivik et al., 2002a). UNEP presented several guidelines for compiling inventories of PCBs (UNEP, 1999; Newton, 2000). Extensive investigations to $\mathrm{PCB}$ emission inventory have been conducted in the United States of America (U.S.A), Canada, Italy, Mexico, and Japan (Shi, 2005). Breivik et al. (2002a, b) have estimated that about 1.5 million t PCB products in the globe were used and 440 to $91700 \mathrm{t}$ of them $\left(\Sigma \mathrm{PCB}_{22}\right)$ were emitted into the environment between 1930 and 2000. Their emission inventory reported that $\Sigma \mathrm{PCB}_{22}$ emission from China ranged from 3.8 to $782 \mathrm{t}$ during 1960-2010 (Breivik et al., 2007). However, this inventory was calculated aiming at presenting the "big picture" of the global PCB air emission. Their estimated total emission in China varied two orders of magnitude and did not take into account unintentional production and soil emissions which would underestimate PCB emissions in China. Existing PCB emission inventories in China were kept updating during the last decade (Breivik et al., 2002b, 2016; Cui et al., 2015) but none of them covers all the emission processes of regional significance. A relatively accurate and comprehensive inventory is, therefore, still needed.

The multimedia mass balance models make it possible to explore PCB budget and assess emission inventory in China. Previously, those models use quantitative source inventory of chemicals to estimate their environmental behaviors and fate. The model performances have been extensively demonstrated and used as a powerful tool for understanding the behavior and fate of chemicals in the environment (MacLeod et al., 2010), which provides an opportunity to screen out potential PCB inventory through finding good agreement between modeled and observed data in the environment. Among indicator PCBs (PCB-28, -52, $-101,-118,-138,-153$, and -180 ) commonly detected in observations, high molecular weight PCBs with relatively low LRAT potential can be used for simulation to exclude the effect of LRAT, a significant source from adjacent countries (Sheng et al., 2013). Therefore, PCB-153, a compound with high detection rates in field observations, was selected as the exemplary compound in this study. Intensive numerical experiments were performed in the present study aiming at: 1) estimating the historical production, 2) developing a proper scheme to optimize settings of emission model and 3) filling the gap between emission inventories and field observations.

\section{Methods}

Fig. 1 is a flowchart showing the procedure of emission inventory construction. As shown, firstly, total PCB usage in China was estimated by linear regression with historical generating capacity. Gridded (1/ $4^{\circ} \times 1 / 4^{\circ}$ latitude/longitude) historical PCB usage were interpolated using electricity consumption, installed capacity of power plants and transformer substations from 1965 to 1975, as well as the gridded population and GDP data as the surrogate. Secondly, the emissions of the target PCB were obtained from the emission model originally introduced by Breivik et al. (2002b) and Cui et al. (2015), which have been modified and improved in this study. Finally, Chinese Gridded

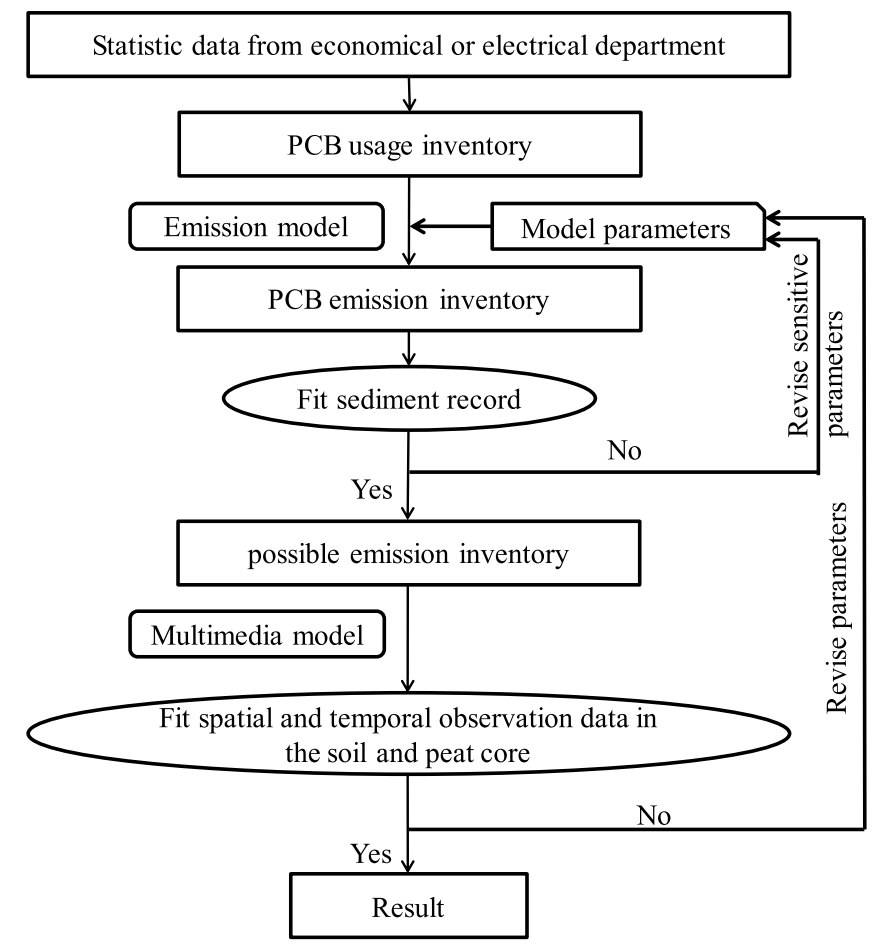

Fig. 1. Flow chart of modeling procedure.

Pesticide Emission and Residue Model (ChnGPERM) was used to assess spatial and temporal patterns of PCB-153 in the environment from 1952 to 2005 using the gridded emission inventory. The modeled PCB-153 concentrations were then used to validate the emission by an optimal agreement between modeled and observed burden in China through extensive numerical experiments.

\subsection{PCB usage}

Historically, two commercial products were manufactured in China from 1965 to 1975 before their ban, namely \#1PCB products (mainly contains trichlorobiphenyls) and \#2PCB products (mainly contains pentachlorobiphenyls). \#1PCB was principally used in manufacturing capacitors that were employed in the electrical supply industry and \#2PCB was mostly used in a wide variety of open systems, such as in oil paints and exterior dopes.

The consumption of \#1PCB in China was mainly related to electrical industries (referred to as power-related PCB in the following text) which could be assessed by generating capacity (Shi, 2005; Shi et al., 2005). The method has been applied in inventory investigation in Italy (Lupi, 2004) and Mexico (CEC, 1996). In China, power-related PCB includes domestic production and a significant amount of PCB-containing products imported between the 1960s and 1970s. To assess the total usage of power-related PCB, we collected generating capacity in the years when PCBs were banned and PCB consumption in electrical equipment of ten countries. $\mathrm{PCB}$ usage history in electrical industries of those countries are similar with China. Linear trends between PCB consumption and generating capacity in these countries can be found in Fig. S1, obtained by a simple linear regression model:

$\mathrm{Y}=\mathrm{A}+\mathrm{Bx}$

The consumption of power-related PCB in Chinese electrical industries was therefore assessed by the linear regression equation and generating capacity in China in 1975, which is about $19.3 \mathrm{kt}$. After the estimation, the power-related PCB usage was apportioned among all the provincial-level administrative region in China, including provinces, municipalities and autonomous regions: 
$P p(i)=P t \times \Delta E c(i) / \sum_{i=1}^{n} \Delta E c(i)$

where $P p(i)$ is the PCB usage in the ith province, municipality or autonomous region, $P t$ is total PCB usage in China, $n$ is total number of Chinese provinces, municipalities and autonomous regions, and $\Delta E c(i)$ is the additional power consumption in each area between 1964 and 1975.

Annual PCB consumption in each province, municipality or autonomous region was further distributed by additional annual generating capacity between consecutive two years according to the following equation:

$P a(i, j)=P p(i) \times \Delta E c(i, j) / \sum_{j=1965}^{1975} \Delta E c(i, j)$

where $P a(i, j)$ is annual PCB usage in a provincial-level administrative region, $\Delta E c(i, j)$ is additional electricity consumption in that region in the $j$ th year, which equals annual electricity consumption of the ith province in the $j$ th year minus that in the $(j-1)$ th year.

PCB emissions might not be correlated well with population density at regional scale (Shanahan et al., 2015). Spatially usage was distributed using a new database including development periods, locations and installed capacities of about 3000 power plants or transformer substations established during PCB usage period (Fig. S4) and population density in the present study. The annual power-related PCB usage inventory at a resolution of $1 / 4^{\circ} \times 1 / 4^{\circ}$ latitude/longitude in each province-level administrative division were obtained by:

$P(i, j, k, m)=P a(i, j) \times F \times C(k, m) / \sum C(k, m)$

where $k$ and $m$ are geographical index of model grid ( $k$ column, $m$ row). For the grid $(k, m)$ located in the ith province, $P(i, j, k, m)$ is the PCB usage in the $j$ th year interpolated by the installed capacity of power plants and transformer substations from 1965 to 1975 as a surrogate, $C(k, m)$ is the installed capacity of power plants or transformer substations at the $(k, m)$ grid collected from electric power department, electric power industry volunteers, and chorography (http://www. gzlib.org/ $), \Sigma C(k, m)$ is the total installed capacity in the ith province, and $F$ is the fraction of PCB used in large scale power plants or transformer substations. An empirical value of $\mathrm{F}$ will be selected which gives the best model performance (Supporting Information, SI). For those grids without documented power plants or transformers, gridded population density data, $D(k, m)$, were used as a surrogate to estimate the PCB usage:

$P(i, j, k, m)=P a(i, j) \times(1-F) \times D(k, m) / \sum D(k, m)$

As for \#2PCB, a total of $1000 \mathrm{t}$ was used in a wide variety of open systems in China (SEPAC, 2003). This product was mainly used in oil paints and exterior dopes, which are more likely associated with economic activities. Therefore, the annual \#2PCB usage in a province, municipality or autonomous region was calculated by the similar models with GDP as a surrogate (SI).

\section{2. $P C B$ emission model}

Historical PCB emissions came from commercial PCBs products which were intentionally used in industry (referred to as IP-PCBs), including \#1PCB and \#2PCB products, unintentionally emission as byproducts of unintentionally processed (referred to as UP-PCBs), and emissions from discarded electrical and electronic equipment waste (referred to as EW-PCBs). UP-PCBs and EW-PCBs emissions were estimated following the method provide by (Cui et al., 2015), of which certain emission factors were updated in China. Detail calculation can be found in SI.

The estimation of IP-PCB emission follows Cui et al. (2015) and Breivik et al. (2002b) with following modifications: 1) Four usage categories were taken into consideration. These are: open usage (U1), domestic small capacitors (U2), domestic large closed systems (U3) and imported large closed system (U4). The relative contributions of individual PCB congener to $\Sigma \mathrm{PCB}_{\mathrm{S}}$ are different between domestic and imported large closed systems. 2) The relative proportions in \#1, \#2 and imported PCBs (Table S1) and their usage categories (Table S2), anticipated ranges of lifetime, accidental release factors, and disposal factors (Table S2) were revised according to PCB usage status in Government reports or literature of China (details in Section Section 1.2.3 of SI). 3) Besides atmospheric emissions discussed in previous studies (Breivik et al., 2002b), PCB release into the soil was also included in the present model. Historically, there were no proper management measures to stop the leakage into soil when disposal PCB-containing products. In the processes of accidental releases to soils, landfill and destruction, a portion of PCBs $\left(e f_{\text {air }}\right)$ were emitted into the air (Breivik et al., 2002b) and the rest were assumed to be emitted into the soil (1$e f_{\text {air }}$. 4) In usage and disposal processes, PCB were primarily emitted into the air and soil. Secondary emissions from water, soil and sediments and degradations in those environmental media were not considered in the emission model because those processes will be calculated by the multimedia mass balance models in the next step.

\subsection{Multimedia environmental fate model}

Combining the IP- and UP-PCB emissions, extensive model scenario simulations were carried out by a multimedia environmental fate model (ChnGPERM). The model has been used in numerical studies of POPs in China and Asia (Tian et al., 2011, 2012; Xu et al., 2013) and proved to be useful in modeling the environmental fate of POPs. Briefly, ChnGPERM includes transfer and transport modules. The transfer module describes concentration variation and inter-compartmental transfer of the target compound in soil, water, sediment, and atmospheric surface layer (ASL, 0-100 m) based on a level IV fugacity approach (Wania and Mackay, 1995). The transport module, using a Lagrangian approach, solves horizontal and vertical mass exchange of the chemical among different grid cells in the ASL, the planetary boundary layer (PBL, 100-1000 m) and the low troposphere (ALT, 1000-4000 m). The detailed structure and physical/chemical processes included in the model have been described elsewhere (Tian et al., 2011). In the present investigation, the physicochemical properties of the target PCB (PCB153) used in the simulation were listed in Table S3.

\subsection{Observation data for comparison}

To evaluate the estimated inventories in the present study, PCB-153 data in relatively stable environmental media, such as soil, sediment, and peat core across China, were collected to compare with the modeling results using the PCB inventory. So far relevant data are still limited (Ren et al., 2007; Pan et al., 2010; Bigus et al., 2014). Four sets of data were selected for comparison. The first dataset is $\Sigma$ PCBs concentrations in sediment cores collected from China. According to Table S2, there are a large number of combinations of parameter settings of PCB emission model, which are impossible to be evaluated individually. Instead, some sensitive parameters were determined by comparing the temporal emission trend with historical records of PCBs in the sediment cores. Cautions should be taken in using that dataset (Section 1.4 of SI). It was only used to evaluate the output of PCB emission model. The second set is individual PCB congener concentrations in the peat core collected on May 24, 2006 at the Zoigê-Hongyuan bog $\left(32^{\circ} 47^{\prime} \mathrm{N}\right.$, $\left.102^{\circ} 31^{\prime} \mathrm{E}\right)$ from the northeast Tibetan Plateau. Deposition records are generally influenced by local sources. The remoteness of this site and high organic carbon content in the peat core enable the samples to record the overall trend of long-term settling of POPs in China (Xu et al., 2013). The third dataset is soil concentration data of PCB-153 from national-wide observation campaigns in 2005 (Ren et al., 2007). The forth dataset is air concentrations in 2004 (Jaward et al., 2005). Details of those datasets is presented in SI. Since most of the observation data for model evaluation were obtained in 2005 and valid 
statistical data started to be reported by the National Bureau of Statistics of China in 1952, numerical simulations of the representative emission scenarios were performed only from 1952 to 2005 .

\section{Results and discussion}

\subsection{PCBs use}

Total power-related PCB usage was estimated by regression analysis. Significant linear relationship between generating capacities in the years when PCBs were banned in ten countries and their total PCB usage in electrical industry was shown in Fig. S1. According to the linear trend and the generating capacity in 1975 reported by the National Bureau of State Statistics (DCSNBS, 2010), the consumption of PCBs in Chinese electrical industries was about $19.3 \mathrm{kt}$. Zhang et al. (2010) estimated the total usage of power-related PCBs of $20 \mathrm{kt}$ in China. Several investigations adopted a lower value $<10 \mathrm{kt}$ (Breivik et al., 2002a; Cui et al., 2015). However, the amount of PCB usage estimated by Chinese government ranged from 14 to $14.5 \mathrm{kt}$ and an unknown number of large transformers containing PCB oils were imported (SEPAC, 2003). We collected PCB-153 concentrations in Chinese soils (Ren et al., 2007) and correlated them with installed capacity of power plants and transformer substations, population or GDP at the same location. Concentrations of PCB-153 ( $\mathrm{r}=0.48-0.79, p<0.001$, $\mathrm{n}=67$ ) were significantly correlated to GDP and installed capacity (Fig. S13). Based on the correlation, PCBs residues in Chinese soils can be derived by regressing PCBs soil concentrations into gridded GDP or installed capacity in China (Eq. (s4)). This yields PCB-153 soil residue of 55.9-100 $\mathrm{t}$ in China. Since $10 \mathrm{kt}$ PCBs only contain $29.8 \mathrm{t}$ PCB-153 according to composition of \#1PCB and \#2PCB products in China, it is deducible that a total PCB usage value larger than $10 \mathrm{kt}$ should be closer to real application status in China. Chinese government reported that about $1 \mathrm{kt} \mathrm{\# 2PCB}$ and $9 \mathrm{kt} \# 1 \mathrm{PCB}$ were manufactured in China, $4.5 \mathrm{kt}$ PCB was imported as capacitors, but imported transformers were still uncertain (SEPAC, 2003). Therefore, we assumed that the total PCB usage was $20.3 \mathrm{kt}$, including $1 \mathrm{kt}$ \#2PCB products, $9 \mathrm{kt} \# 1 \mathrm{PCB}$ products, $10.3 \mathrm{kt}$ imported $\mathrm{PCB}-$ containing capacitors and transformers.

The temporal trend of power-related PCB usage was determined by the additional power consumption in each provincial-level administrative region of China (Eqs. (2)-(3)), and the spatial pattern of the PCB usage was evaluated using the locations of installed capacity of power plants and transformer substations, and population density as the surrogate (Eqs. (4)-(5)). Although detailed data have not been reported yet, Zhang et al. (2010) estimated the PCB usage in eastern, central, and western China were about $45.5 \%, 31.5 \%$ and $23.1 \%$ of the national total using population density as the surrogate, respectively. According to our estimation in this study, PCBs were mainly used in eastern and central China which contributed $44.5 \%$, and $36.6 \%$ to the national total usage, respectively, similar to the previous estimation (Zhang et al., 2010). The spatial trend of PCB usage is determined by installed capacity, population density and parameter F (Eqs. (4)-(5)), so the screening process using emission model and multimedia model in Fig. 1 was firstly applied to determine an empirical value $\mathrm{F}$ (Details are illustrated in Fig. S14). When F lies between 0.4 and 0.8 , the correlation coefficient between modeled soil concentrations and measured data were higher than other scenarios (Fig. S15). Hence, F was temporarily set as 0.6. The temporal and spatial trends of power-related PCB usage are presented in Fig. 2. Likewise, \#2PCB products usage was interpolated using GDP as the surrogate (SI). Results are illustrated in Fig. 3. As shown, major part of IP-PCBs was used in East China subject to intensive industrial activities and dense population, where has been regarded as potential sources of PCBs in China (Zheng et al., 2014).

\subsection{Sensitivity of PCB emission model}

Overall, PCB emissions are controlled by model parameters like emission factors, spillage or disposal factors (Breivik et al., 2002b) (Table S2), so one of the objectives of this study is to determine possible values of those parameters. Existing information of PCB usage and emission in China from relevant Government departments reports or literature are vague and the estimated emissions are affected by many emission model parameters. As a result, the modeled PCB usage and emissions might be subject to large uncertainties. Before determining model parameters, sensitivity and uncertainty analysis of the PCB emission model should be carried out to spotlight important factors (Section 3 of SI). Similar to the previous emission model (Breivik et al., 2002b), the influence of uncontrolled fires and open burning were also taken into consideration in the present study, which can be further clarified by emission models. PCB emissions from different processes and sectors can be summarized into two equations:

$E_{\text {air }}=U_{\text {rem }} \times p f \times e f_{\text {air }}$

$E_{\text {soil }}=U_{\text {rem }} \times p f \times e f_{\text {soil }}$

where $p f$ is the fraction of products related to a certain process, which equals accidental release factors or disposal factors in Table S2, $e_{\text {air }}$ and $e f_{\text {soil }}$ are emission factors for the air and soil, respectively. At each time step of calculation, $\mathrm{U}_{\mathrm{rem}}$ are constant for all the processes, so emissions $\left(E_{\text {air }}\right.$ and $\left.E_{\text {soil }}\right)$ can be determined by $p f \times e f$ (referred to as apparent emission factor, $A E F$ ). The range of $p f$, ef and AEFs were listed in Table S4. For air emission, $A E F_{\text {air }}$ from accidental releases by fire, open burning and usage emissions for U1 products were several order of magnitudes higher than other $A E F_{\text {air }}$, suggesting that air emission results are sensitive to $e f_{\text {usage }}$ of $\mathrm{U} 1$ products, $a f_{a, f}$, and $d f_{o}$. The values of $A E F_{\text {soil }}$ from accidental release into soils, destruction and landfill are close to each other, indicating that the influences of $a f_{a, s}, d f_{d}$ and $d f_{l}$ should be similar. Degradation was not taken into account in the present PCB emission model. Based on the mass balance approach of PCB emission model, it should be also note that only burning can remove PCBs permanently. $e f_{\text {soil }}$ from the accidental releases to soils, landfills, and destruction determines the emission partition between air and soil, but total emissions would be identical.

Average product lifetimes mainly influence the temporal trends of emissions. High emissions generally occurred after the beginning of disposal of PCB-containing products applied from 1965. With fixed lifetimes, the temporal trends of air and soil emissions are presented in Fig. S17. Air emissions started to increase in the year of $\left(1965+\mathrm{LF}_{\mathrm{U} 1}\right)$, whereas soil emissions began to increase in the year of $\left(1965+\mathrm{LF}_{\mathrm{U} 2}\right)$, $\left(1965+\mathrm{LF}_{\mathrm{U} 3}\right)$ or $\left(1965+\mathrm{LF}_{\mathrm{U} 4}\right)$. In the case of PCB-153, the mass percentage in U2 and U3 products were significantly low (Table S1) and thus lifetimes of U1 and U4 products became important.

\subsection{Parameter settings in emission model}

The possible settings of sensitive parameters were chosen by finding good agreement between temporal trends of emissions and sediment core record. In Fig. S8, PCB concentrations in sediment samples started to increase after 1968, 1983 and 1994, which means either air or soil emissions should also increase in the three periods. Relatively low emissions should occur around 1980. Fig. S17 shows the rapid increase of the emission which often indicates that the first batch of some usage category products start to reach their use-life expectancy. Relatively short lifetimes will lead to high emissions in 1980 (Fig. S17(a)) or low emissions after 1995 (Fig. S17(b)). Therefore, relatively long lifetimes were selected in this emission modeling $(20,15,30$ and 30 years for U1, $\mathrm{U} 2$, U3 and U4 products, respectively). With those fixed lifetime values, soil emissions can always increase near 1995, while the temporal trends of air emissions varied with accidental release factors ( $a f_{a, s}$ and $a f_{a, f}$ ) and disposal factors ( $d f_{o}, d f_{d}, d f_{l}$, and $d f_{s}$ ) (Fig. S18). In low emission scenario (scenario 1, low accidental release and disposal factors) shown in Fig. S18, neither air nor soil emissions decline as seen in the sediment observation, indicating low $a f_{a, s}, a f_{a, f}$ and $d f_{o}$ inevitable results in small 


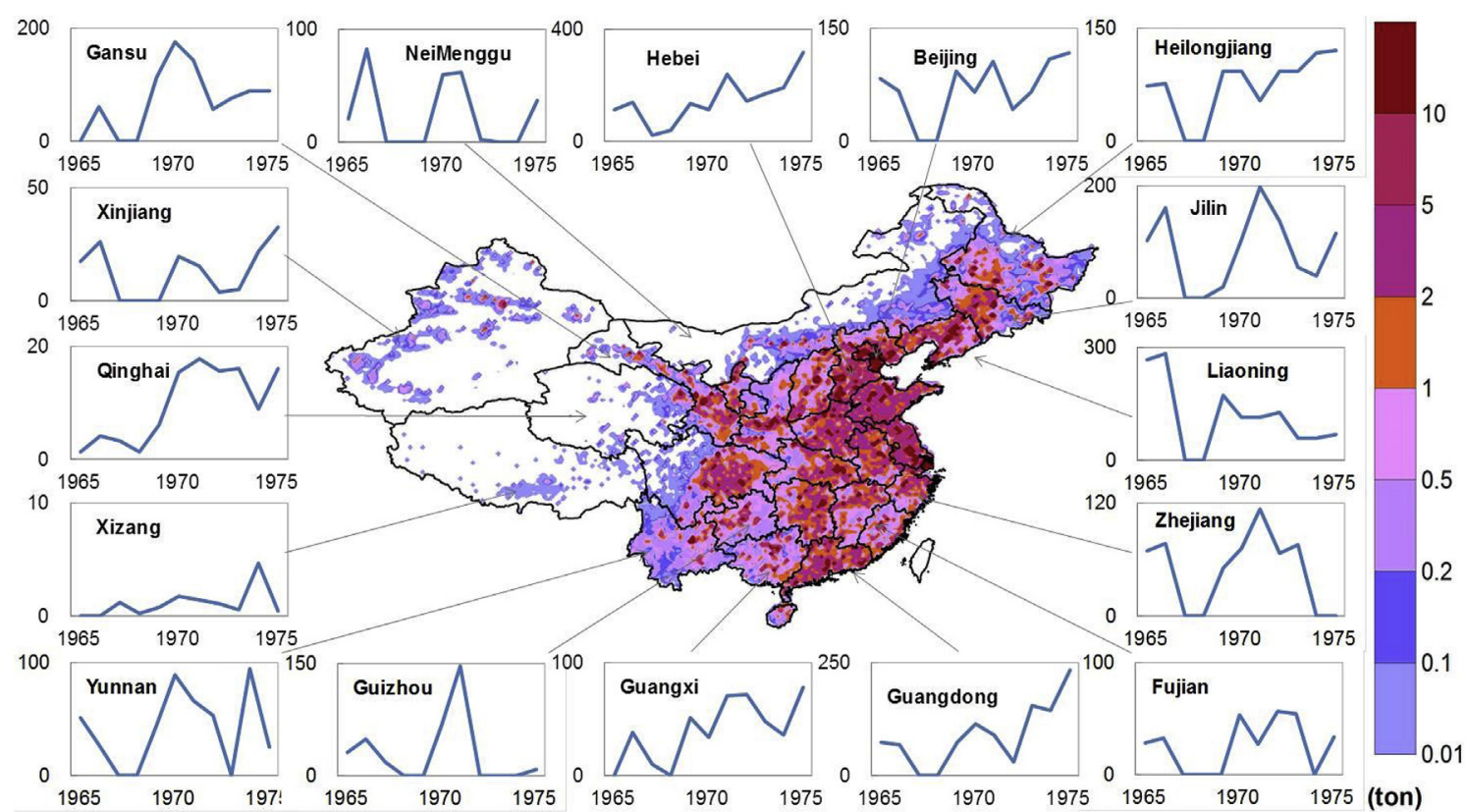

Fig. 2. Spatial pattern of power-related PCB usage in China during 1965-1974. Temporal usages of sixteen provinces are presented as an example.

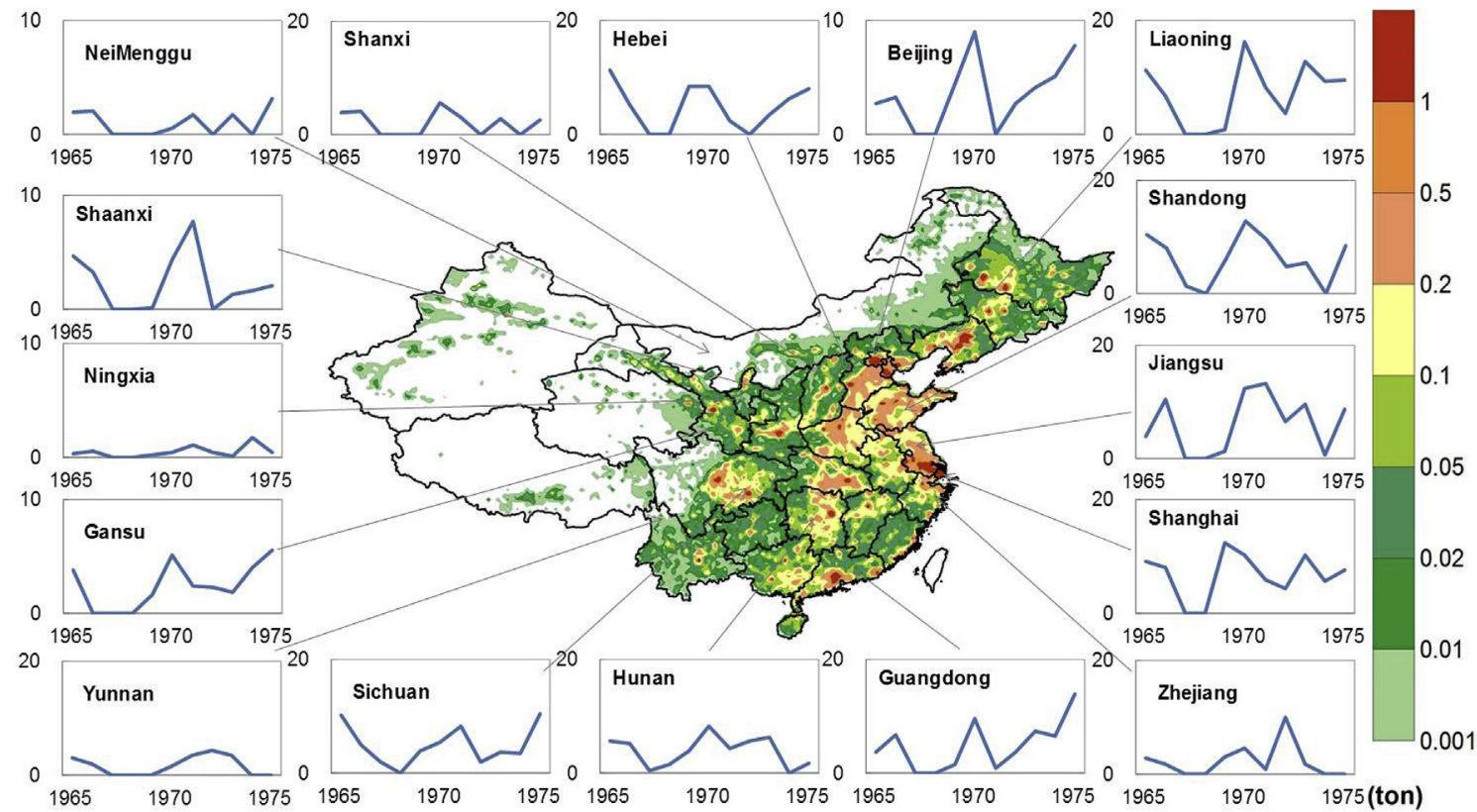

Fig. 3. Spatial pattern of \#2PCB usage in China during 1965-1974. Temporal usages of sixteen provinces are presented as an example.

Table 1

The recommended of parameters used in the PCB emission model.

\begin{tabular}{lllll}
\hline & $\mathrm{U} 1$ & $\mathrm{U} 2$ & $\mathrm{U} 3$ & $\mathrm{U} 4$ \\
\hline $\mathrm{F}$ & $0.4-0.8$ & & & \\
Lifetime (years) & 20 & 15 & 30 & 30 \\
& & & & \\
Accidental release factors & $\left(\right.$ year $\left.^{-1}\right)$ & & & \\
Soils $\left(\mathrm{af}_{\mathrm{a}, \mathrm{s}}\right)$ & - & $0.008-0.016$ & & \\
Fires $\left(\mathrm{af}_{\mathrm{a}, \mathrm{f}}\right)$ & 0.002 & & & - \\
& & & & \\
Disposal factors $\left(\right.$ year $\left.^{-1}\right)$ & & & & \\
Open burning $\left(\mathrm{df}_{\mathrm{o}}\right)$ & $0.04-0.1$ & $0.001-0.002$ & - & $-15-0.25$ \\
Destruction $\left(\mathrm{df}_{\mathrm{d}}\right)$ & - & $0.01-0.1$ & $0.15-0.25$ & \\
Landfill $\left(\mathrm{df}_{\mathrm{1}}\right)$ & - & - & $0.1-0.25$ & \\
Storage $\left(\mathrm{df}_{\mathrm{s}}\right)$ & - & - &
\end{tabular}

peak near 1975 and 1985. If only increasing disposal factors (scenario 2 , low accidental release and high disposal factors), it will lead to the absence of peak in 1975 but the occurrence after 1985. Temporal trends of total air emission mainly are related to emissions from U1 products which are sensitive to $d f_{o}$ of U1. This suggests that relatively high accidental release factors and $d f_{o}$ should be adopted in the next step. To guarantee the total emission to decrease after 1975 and increase after 1985 , the minimum values of $a f_{a, f}, a f_{a, s}$ and $d f_{o}$ should be at least taken as $0.002,0.008$ and 0.04 , respectively (scenario 3 in Fig. S18). The maximum values of accidental release and disposal factors in Table S2 can also generate the three emission peaks (scenario 4 in Fig. S18). Therefore, we considered that the parameter settings of potential inventory should lie between the values of scenario 3 and 4 , namely, $a f_{a f}$ should be 0.002 and $d f_{o}$ for $\mathrm{U} 1$ products should range from 0.04 to 1.0. Other minor parameters were adjusted following the procedure in 

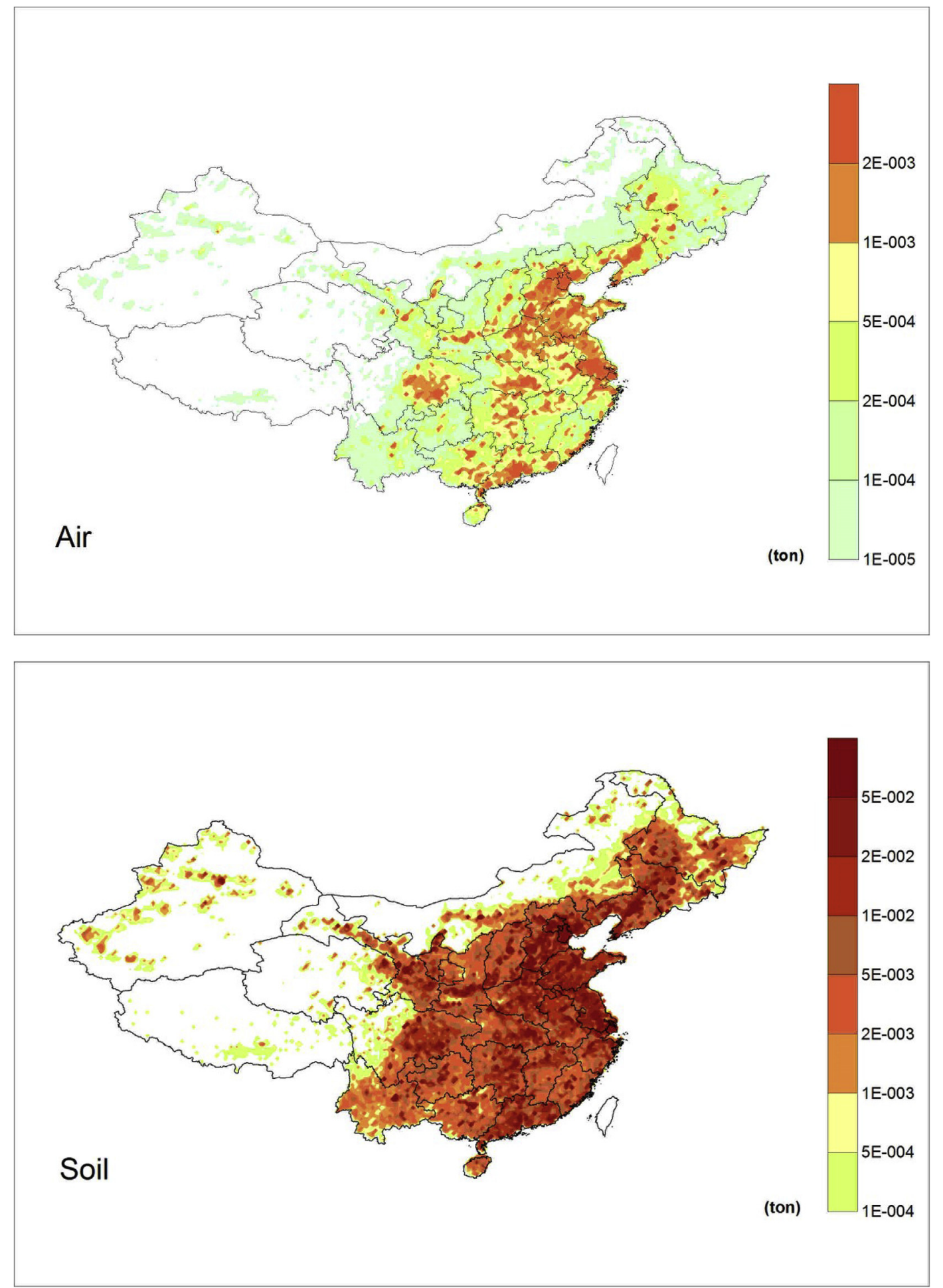

Fig. 4. Spatial pattern of air and soil PCB-153 emission in China from 1952 to 2005.

Fig. 1. Within possible range of lifetimes, accidental release factors and disposal factors, representative emission scenarios (low, middle, high values of parameters) were used to model historical PCB-153 deposition and residues in the environment by ChnGPERM. Emission scenarios were evaluated by comparing the model output and field observations. Scenarios with better simulation results were selected (Table 1). Some sensitive parameters were, to some extent, in line with those presented by Breivik et al. (2007). The data in Table 1 may present an average condition in China. In those scenarios, three emission peaks in the peat core record should be found in the modeled data (Fig. S19). Although the modeled deposition fluxes somewhat lagged behind the measured concentration, it could be related to downward leaching as reported in previous comparison studies (Xu et al., 2013). The Pearson correlation coefficient of the modeled and measured soil concentrations ranged from 0.70 to $0.71(p<0.01)$, and the simulated concentrations are generally in the same order of magnitude with those monitored values (Fig. S20). This suggests that the improved inventory could represent the spatial characteristics of PCB emission in China to a large extent. 

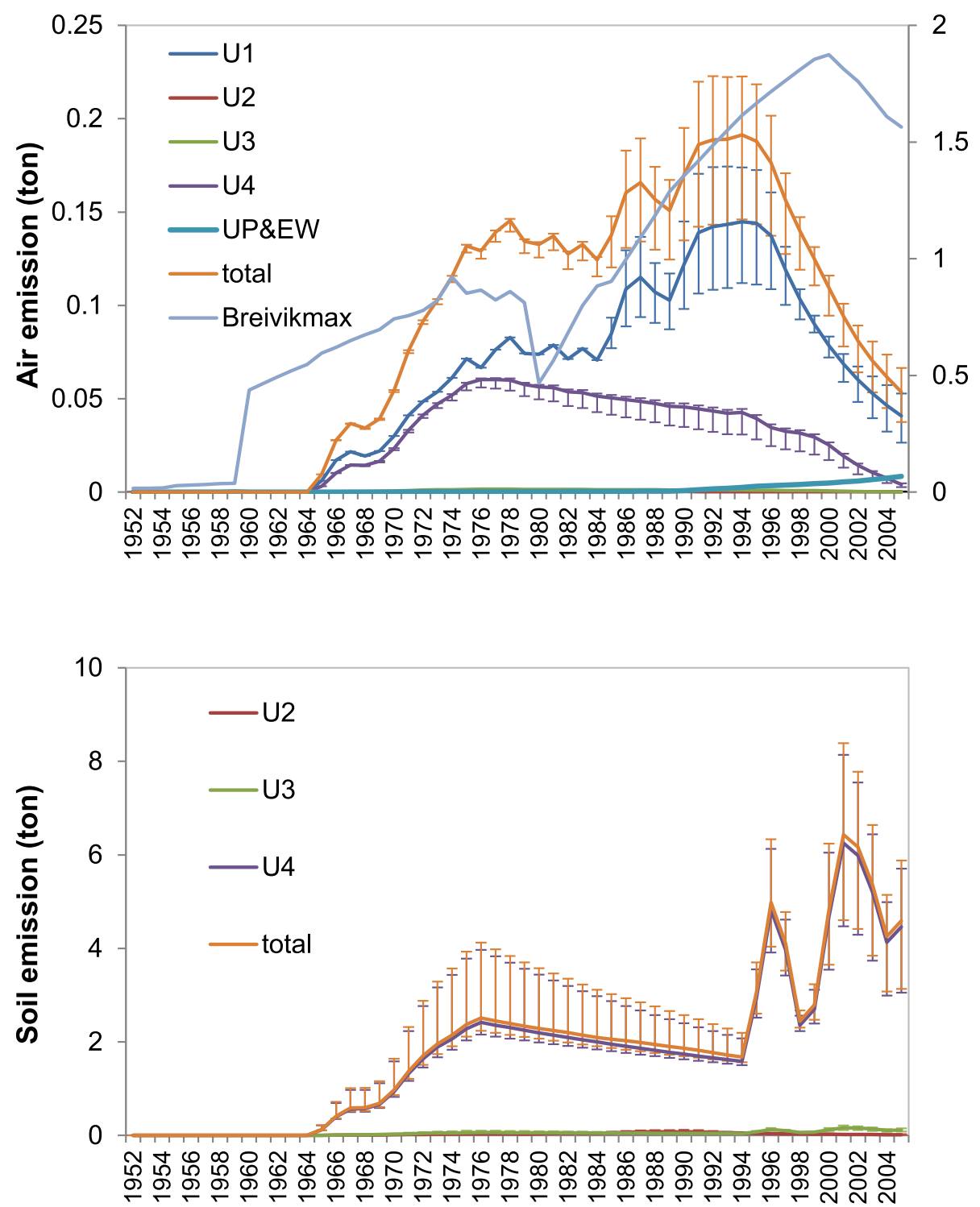

Fig. 5. Historical trends of PCB-153 emissions from open usage (U1), domestic small capacitors (U2), domestic large closed systems (U3), imported large closed system (U4) category products and unintentional production (UP) in China using the selected model parameters in Table 1. The worst PCB-153 emissions in China from 1952 to 2000 from Breivik et al. (2016) are also presented for comparison.

\subsection{Temporal and spatial distribution of emissions}

Using the selected model parameters in Table 1, gridded PCB emissions from 1952 to 2005 were estimated. Here the average PCB153 emission scenario in China will be elaborated as an example. 20.3 kt IP-PCB products used in China contain $179 \mathrm{t}$ PCB-153, of which about $2.7 \%(4.79 \mathrm{t})$ were emitted into the air, $56.4 \%(101 \mathrm{t})$ entered into the soil, and about $20.8 \%$ (37.3 t) were either in service or sealed in storage sites until 2005. Since substantial amount of PCB-153 remained in the soil, the result indicates that PCB contaminations in the environment may not easily decline after 2005. UP-PCB and EW-PCBs contributed a relatively minor part to total historical emissions, with a total of 0.07 t. From 1952 to 2005, about 106 t PCB-153 were emitted or disposed into the environment. $4.6 \%$ of them were into the air and $95.4 \%$ were into the soil in that scenario. Spatially variations of PCB153 emission are similar to that of PCB usage (Fig. 4). High emissions mainly occurred in densely populated areas in eastern China.

Historical trends of PCB-153 emissions were plotted in Fig. 5, which were primarily related to usage and disposal. From 1965 to 1975 PCBcontaining products were continuously applied in China, and thus emissions kept increasing. After its ban in 1975, PCB-153 emission gradually decreased. However, such the decrease trend were interrupted by disposal processes. In 1985, air emissions started to increase when the first batch of products in U1 category was disposed (mainly by open burning). Similarly, soil emissions significantly increased in 1995, when products in U4 categories started to be disposed by destruction, landfills and storage. The three peaks in sediment records (Fig. S8) represent the beginning of PCB usage (air and soil), disposal of U1 products (air) and disposal of U4 products (soil), respectively. Imported PCB-containing devices (U4) contributed a significant part of historical emissions. Given that primary atmospheric emission of IP-PCB has declined since the 1990s, secondary emission from soils, UP-PCB and reemission from storage sites should be a long-lasting issue in PCB management in the future.

The annual PCB-153 emissions from 1952 to 2005 by Breivik et al. (2016) are also illustrated in Fig. 5. Their estimated atmospheric PCB153 emissions in China ranged from 0.057 to $8.8 \mathrm{t}$ (Breivik et al., 2007). In worst emission scenario, the amount can reach $49.6 \mathrm{t}$ (Breivik et al., 2016). Our estimated air and soil PCB-153 emissions from IP-PCB were $4.9 \mathrm{t}$ and $101 \mathrm{t}$, respectively, with a total of $106 \mathrm{t}$. The new inventory 
can yield 55.9 to 100 t PCB-153 residues in Chinese soils. The two inventories were processed by ChnGPERM model and results are presented in Figs. S20 and S21. Compared with the worst scenario of previous inventory, the output of average concentration levels and spatial variations of improved inventory are closer to measured data. Also, sediment recorded emission peaks were also identified (Fig. 5). As Breivik et al. (2007) noted, their emission estimations were subject to substantial uncertainties. Our improved inventory provides more reasonable estimate of on historical PCB emissions in China.

\subsection{Further discussion}

Although the present inventory provided a relatively reliable dataset for PCB estimation and modeling, significant uncertainty still exists and cautions should be taken before using the inventory. First, the estimation of PCB usage depends on the assumption that PCB usage is linearly correlated with electrical consumption and therefore with installed capacities of electric generator or transformers. The power facilities data should be an important factor influencing the accuracy of inventory. A portion of power facilities owned by enterprise or groups were not documented by Chinese electricity utilities, which would result in underestimation of PCB emissions in certain areas. For example, the modeled PCB-153 concentrations in Yunnan and Sichuan provinces (U05, U06, R23 in Fig. S11) were about an order of magnitude lower than the measured value, which could be attributed to the fact that the power facilities in large-sized iron and steel factories in those areas were not recorded. Also, electrical equipment out of service has been collected at temporary storage sites in accordance with the requirements proposed by relevant government agencies. The number of those storage sites is presently unknown. It has been reported that some of these sites are approaching their design lifetime of 20 years (SEPAC, 2007), and thus leaking PCBs into the surrounding environment. Identification of these sites and the estimate of PCB emissions from these sites will be time-consuming and costly which were not taken into consideration in the present study. Second, the data on historical EFs, lifetime and disposal factors of PCB-containing equipment were vague in China. In the model evaluation stage, several combinations of emission and disposal factors can yield good model performance. The result presented in this study is a representative scenario which fits observation data better. However, the historical emissions recorded in sediment cores varied sites by sites. Some other parameter combinations could be more suitable than those in Table 1 at specific sites. We strongly recommend that these sediment records and other reliable documents should be used as references to replace those values in Table 1 when calculating local PCB emissions. As we suggested above, this is a preliminary study to present an emission inventory of PCB-153 which can be used in regional multimedia models to elucidate, environmental fate, and mass balance of PCBs. Emissions and environmental fate of individual PCB congeners varied significantly. The refinement of emission model and comprehensive inventories of other PCBs will be investigated in the future.

\section{Conclusion}

Previous PCB inventories are difficult to yield present PCB soil residues in China, which may significantly underestimate soil emission. In this study, we generated PCB-153 emission inventory with a resolution of $1 / 4^{\circ}$ latitude $\times 1 / 4^{\circ}$ longitude in China from 1952 to 2005 as an example. Based on generating capacities, we estimated that about 20.3 kt PCBs were applied in the past, which contains 179 t PCB-153. Spatially, high emissions mainly occurred in densely populated areas in eastern China. Temporally, air emissions increased after 1968 and 1984, while soil emissions did after 1968 and 1994. The peak in 1968 was associated with PCB usage emission, and the latter two peaks with the disposal of PCB-containing products. Until 2005, the proportions of PCB-153 emission into the soil, air and storage category were $56.4 \%$,
$2.7 \%$ and $20.8 \%$, respectively. Primary emissions in China has gradually declined recently, but secondary emission from soils, unintentionally produced PCBs (UP-PCB), and reemission from storage sites could be a long-lasting issue in the future.

\section{Acknowledgements}

The authors appreciate the financial support from the National Natural Science Foundation of China (NSFC) (no.: 41403106, 414300417, 41673133, 71403118 and 41101495), and National Key R \&D Program of China (ATMSYC, 2017YFC0212000).

\section{Appendix A. Supplementary data}

Supplementary data related to this article can be found at http://dx. doi.org/10.1016/j.atmosenv.2018.04.013.

\section{References}

Bigus, P., Tobiszewski, M., Namiesnik, J., 2014. Historical records of organic pollutants in sediment cores. Mar. Pollut. Bull. 78, 26-42.

Breivik, K., Armitage, J.M., Wania, F., Sweetman, A.J., Jones, K.C., 2016. Tracking the global distribution of persistent organic pollutants accounting for e-waste exports to developing regions. Environ. Sci. Technol. 50, 798-805.

Breivik, K., Sweetman, A., Pacyna, J.M., Jones, K.C., 2002a. Towards a global historical emission inventory for selected PCB congeners - a mass balance approach: 1. Global production and consumption. Sci. Total Environ. 290, 181-198.

Breivik, K., Sweetman, A., Pacyna, J.M., Jones, K.C., 2002b. Towards a global historical emission inventory for selected PCB congeners - a mass balance approach: 2. Emissions. Sci. Total Environ. 290, 199-224.

Breivik, K., Sweetman, A., Pacyna, J.M., Jones, K.C., 2007. Towards a global historical emission inventory for selected PCB congeners - a mass balance approach: 3. An update. Sci. Total Environ. 377, 296-307.

CEC, 1996. Status of PCB Management in North America. Comission For Environmental Cooperation.

Cui, S., Fu, Q., Ma, W.L., Song, W.W., Liu, L.Y., Li, Y.F., 2015. A preliminary compilation and evaluation of a comprehensive emission inventory for polychlorinated biphenyls in China. Sci. Total Environ. 533, 247-255.

DCSNBS, 2010. China Compendium of Statistics 1949-2008. Department of Comprehensive Statistics of National Bureau of Statistics of China. China Statistics Press, Beijing.

Jaward, F.M., Zhang, G., Nam, J.J., Sweetman, A.J., Obbard, J.P., Kobara, Y., Jones, K.C., 2005. Passive air sampling of polychlorinated biphenyls, organochlorine compounds, and polybrominated diphenyl ethers across Asia. Environ. Sci. Technol. 39, 8638-8645.

Liu, L.Y., Ma, W.L., Jia, H.L., Zhang, Z.F., Song, W.W., Li, Y.F., 2016. Research on persistent organic pollutants in China on a national scale: 10 years after the enforcement of the Stockholm convention. Environ. Pollut. 217, 70-81.

Lupi, C., 2004. Introduction International Inventory Experience: Italy, Europe and Other Contries, China. SEPA.

MacLeod, M., Scheringer, M., McKone, T.E., Hungerbuhler, K., 2010. The state of multimedia mass-balance modeling in environmental science and decision-making. Environ. Sci. Technol. 44, 8360-8364.

Newton, M., 2000. Compiling national inventories of PCBs. In: UNEP Chemical Workshop on the Management of Polychlorinated Biphenyls (PCBs) and Dioxins/Furans. UNEP Chemicals, Yaounde Cameroon.

Pan, X.H., Tang, J.H., Li, J., Guo, Z.G., Zhang, G., 2010. Levels and distributions of PBDEs and PCBs in sediments of the Bohai sea, north China. J. Environ. Monit. 12, 1234-1241.

Ren, N., Que, M., Li, Y.F., Liu, L., Wan, X., Xu, D., Sverko, E., Ma, J., 2007. Polychlorinated biphenyls in Chinese surface soils. Environ. Sci. Technol. 41, 3871-3876.

SEPAC, 2003. Building the Capacity of the People's Republic of China to Implement the Stockholm Convention on POPs and Develop a National Implementation Plan. State Environmental Protection Administration of China.

SEPAC, 2007. National Implementation Plan for the Stockholm Convention on Persistent Organic Pollutants State Environmental Protection Administration of China.

Shanahan, C.E., Spak, S.N., Martinez, A., Hornbuckle, K.C., 2015. Inventory of PCBs in chicago and opportunities for reduction in airborne emissions and human exposure. Environ. Sci. Technol. 49, 13878-13888.

Sheng, J.J., Wang, X.P., Gong, P., Joswiak, D.R., Tian, L.D., Yao, T.D., Jones, K.C., 2013. Monsoon-driven transport of organochlorine pesticides and polychlorinated biphenyls to the Tibetan plateau: three year atmospheric monitoring study. Environ. Sci. Technol. 47, 3199-3208.

Shi, W., 2005. China PCB Inventory Methodology and Application Demonstration. M. S. thesis. Tsinghua University.

Shi, W., Yu, G., Huang, J., 2005. International experience for reference in PCBs inventory investigation. in Chinese. Environ. Protect. 06, 70-74.

Tian, C., Liu, L., Ma, J., Tang, J., Li, Y., 2011. Modeling redistribution of $\alpha-\mathrm{HCH}$ in Chinese soil induced by environment factors. Environ. Pollut. 159, 2961-2967. 
Tian, C., Ma, J., Chen, Y., Liu, L., Ma, W., Li, Y.-F., 2012. Assessing and forecasting atmospheric outflow of $\alpha-\mathrm{HCH}$ from China on intra-, inter-, and decadal time scales. Environ. Sci. Technol. 46, 2220-2227.

UNEP, 1999. Guideline for the Identificantion of PCBs and Materials Containing PCBs Geneva, Switzerland. UNEP Chemicals.

Wania, F., Mackay, D., 1995. A global distribution model for persistent organic chemicals. Sci. Total Environ. 160/161, 211-232.

Xing, Y., Lu, Y., Dawson, R., Shi, Y., Zhang, H., Wang, T., Liu, W., Ren, H., 2005. A spatial temporal assessment of pollution from PCBs in China. Chemosphere 60, 731-739.
Xu, Y., Tian, C.G., Zhang, G., Ming, L.L., Wang, Y., Chen, Y.J., Tang, J.H., Li, J., Luo, C.L., 2013. Influence of monsoon system on alpha-HCH fate in Asia: a model study from 1948 to 2008. J. Geophys. Res. (Atmospheres) 118, 6764-6770.

Zhang, Z., Tian, C.G., Jia, H.L., Li, Y.-F., 2010. Gridded Chinese polychlorinated biphenyls ( PCBs) usage inventories. in Chinese. J. Nat. Sci. Heilongjiang Univ. 27, 111-116.

Zheng, Q., Nizzetto, L., Mulder, M.D., Sáňka, O., Lammel, G., Li, J., Bing, H., Liu, X., Jiang, Y., Luo, C., Zhang, G., 2014. Does an analysis of polychlorinated biphenyl (PCB) distribution in mountain soils across China reveal a latitudinal fractionation paradox? Environ. Pollut. 195, 115-122. 